\title{
The Role of Applications in the Support of Electronic Commerce "Application of Instagram as a Model" A Sample of Members of Al-Kamil Community- Saudi Arabia
}

\author{
Abdulnaser S. H. Al-Msloum* \\ University of Jeddah "Alkamil Branch", Jeddah, Saudi Arabia; asalem2@uj.edu.sa
}

\section{Abstract}

Background/Objectives: To identify the determinants of the practice of e-commerce in the full province.

Methods/Statistical analysis: This study used 16 of previous researches as reference. The study was conducted on a sample of members of the full conservative society. The researcher used the descriptive analytical method to suit this study.

- The existence of a relationship between the applications of e-commerce and the customs and traditions of the Saudi society in the province of Al-Kamil.

- A statistically significant relationship between e-commerce applications and the comparative advantages and competitiveness of the organization.

- There is an inverse relationship between the application of the information and the sale and purchase of products and services.

The article recommended the following important issues:

- Adopting the technology education policy for the members of the society in Al-Kamil governorate to demonstrate the importance of electronic commerce through training and education programs in professional and administrative institutions, with the aim of spreading technical awareness in educational and academic institutions in accordance with customs and traditions.

- Resolving the obstacles facing the spread of e-commerce in non-civil societies by providing fast Internet, and raising awareness of the importance and benefits of e-commerce and keeping abreast of the global developments in the process of marketing products through the Internet.

Findings: Instagram application is one of the best and most popular free applications used by users to share and share photos on the Internet, giving users the ability to take photos and video clips, and then share them through the various social networks and the network it. Last month, Windows Phone lacked many features and options, such as shooting videos, alerting users to people in the photos, and not allowing users to take pictures through the application. The researcher finds a set of recommendations calling for taking into account as a future work to be done by others:-

- Adopting the technology education policy for the members of the society in Al-Kamil governorate to demonstrate the importance of electronic commerce through training and education programs in professional and administrative institutions, with the interest of spreading technical awareness in educational and academic institutions in accordance with customs and traditions.

Improvements/Applications: Saudi Arabia is one of the societies of the modern world seeking technological revolution. For decades, Saudi Arabia has witnessed a great turnaround in the transformation of a technical society based on the advantages of communication technology in particular and modern technology in general in all fields. The concept of e-commerce since it has become a real reality, we must deal with it, but there is a significant reluctance in the practice of

*Author for correspondence 
electronic commerce using applications, especially the application of the interest in the society of the province of full one of the provinces of Saudi Arabia. The benefits of Instagram are so many advantages that many people are aware of these benefits and are helping them make money. As well as the potential for social growth and development within this social network, it is also possible to attract ever-increasing numbers of followers. Best of all is the possibility of sharing tastes and preferences as well as ideas that contribute to the development of trends and trends and thus reach the desired target audience.

Keywords: Al Kamil Governorate, Electronic Applications, E-Commerce, iPad, Instagram, Information and Communication Technology ICT, Sources of Information Collection, Twitter, ANOVA and SPSS.

\section{Introduction}

Until recently, Instagram was an immersive photo app that was only available on iPhones. Today, this submerged platform has traditionally become one of the daily habits of millions of users. Having evolved from just a simple application to image filtering, Instagram today builds up a huge number of features that have made your photos more social - to become one of the largest social networks in terms of use for both adults and young people. Initially, the official Instagram task was to beautify your images using a combination of filters and frames such as XPro-II, Earlybird, Lo-fi, Sutro, Toaster, Brannan, Inkwell, Walden, Hefe or Nashville or 1977. But now Instagram has made use of some Features that originally appeared with Snapchat including face filters (masks), live streaming videos, publications as well as the latest launch feature, IGTV. Despite its many advantages, Instagram is distinguished by its ability to create a kind of interaction between its users who are constantly following all those endless videos, photos and publications posted on the Internet. Quickly find content centered around any of your interests by doing a quick search and tag your publications to make them more visible using HCHTAG technology. You can now experiment with a different view of the world from a more local perspective and take a quick look at the snapshots posted by other users wherever they are. You can also link your Instagram account with any of your favorite social networks like Twitter, Facebook, Tumblr, or Foursquare by simply clicking the social sharing button. Of course, Instagram will still be just a simple photo sharing application for many users in essence. But it's also a new way for you to express yourself and explore the world, while maintaining a close relationship with the people you care for and with whom you share your interests. For others, he will continue to give them hours of amazing activities that they can follow. The modern world has witnessed a series of rapid changes in the field of communication and information technology, making the world a global village in which information travels throughout the globe in parts of a second. These changes have a direct impact on the individuals and institutions of societies, Innovators are adapting to make use of the benefits offered in all cases ${ }^{1}$. Saudi Arabia, as one of the societies of the modern world, was not far from this revolution. For several decades, Saudi Arabia has witnessed a great turnaround in the transformation of a technical society based on the advantages of communication technology in particular and of modern technology in general in all fields. Imposed on everyone, and so do not find themselves in isolation from the rest of the world.

The concept of electronic commerce was not as it is now, as these applications did not provide an economically viable alternative to the spread after the technological developments in the wide range of electronics and means of communication where they are available to enterprises and companies of various types and sizes for cheap, small and easy to use. These technological developments have been accompanied by administrative and regulatory transformations in communications, which have led to the liberalization of this important sector of much legislation that monopolize its use and provide traditional services that are limited to the use of telephone networks and do not attach sufficient attention to data transmission services and other advanced services.

Despite the tremendous development of information and communications technology, electronic media and the Internet have been used to distribute and market many products. Sales and purchases between consumers and producers or between companies are carried out using communications technology. The money is transferred in many ways, including Visa cards or electronic checks. This process saves time, improves efficiency and simplifies 
procedures. It also provides a quick response to market demands through interaction with customers, with the ability to interact with more than one source in the same economy. The transaction sends an email to an infinite number of receivers at the same time and without having to resend each time $\stackrel{2,3}{\underline{3}}$.

In this area, the Internet offers limitless possibilities for collective or parallel interaction between an individual and a group. This is unprecedented in any interactive tool, which has become the first platform for free marketing in e-commerce, namely the application of Instagram, which has become an effective tool for promoting many products in the Arab world in general and in the Kingdom in particular. As a result of the high use of "interest" in e-commerce in the Kingdom, it is enough to download the application and then upload the image of the product and modify it and add your contact information such as telephone and e-mail ${ }^{4}$. In light of what has been discussed above, this study is intended to monitor the role of applications in supporting e-commerce as a model for a sample of members of the Al-Kamil community. The reason for the choice of this subject to the emergence and clarity of several effects of the application of the electronic and electronically spread, which made this type of communication under the study and research, especially with the frequency of negatives and the benefits that come day after day in the field of scientific heritage of communication research.

Among the major advantages of Instagram applications, the following: -

- Ease of communication and speed with whom you want from the personalities of scientists or elders or students of science or politicians or writers, analysts or journalists ... Etc.

- Easy to follow the events and the latest news and updates.

- Ease of use in the field of advocacy and dissemination of tips, recommendations, books, research and more.

- Turning the world into a mini-network in which people of all races and types can communicate with incredible ease. I can write a letter to Obama while I am in Sana'a while he is in Washington.

On other hand, among its drawbacks the following:-

- Discussions and debate, which can only benefit from the challenge and insult and harassment among Muslims.
- Revealing the secrets and knowing all about what is going on even in things that are best kept.

- The addiction of some to the extent of forgetting male and worship.

- Exploitation of some of the people in the spread of sedition and lies and rumors and meditations.

- Dissemination of what is harmful to our religion and the serious violations of our faith with the lack of Islamic censorship, which adopts sharia law.

Finally, this article aim to achieve the following targets:-

- The aim of this study is to monitor some electronic applications in support of electronic commerce and then to determine the extent to which these applications can be supported as an application of the Instagram.

- Identify the readiness level of the entire community members to understand and grasp the electronic application system.

- The establishment and settlement of the pillars of information technology in the most prominent applications in support of electronic commerce.

- Provide a scientific reference in the field of electronic commerce literature and related applications such as electronic administration and electronic payment related.

- To identify the problems and obstacles that stand in the way of these technologies in activating electronic commerce and proposing appropriate solutions.

\section{Literature Review of Most Related Works}

Electronic applications are defined as a computer application or program that can be accessed and used through the web or through a network such as the Internet or intranet. Web applications are programmed by descriptive programming languages supported by most modern web browsers, such as: HTML, JavaScript, Java and AJAX. Web applications, a new term in the world of technology, describes in particular the software provided by Web developers through web technologies that emerged at the beginning of 2006. (www.wekedi. com) these are small programs that are downloaded and installed on smart phones or tablets, instead of 
being viewed inside the browser. These applications are loaded based on the type of driver used and which rely on so-called application stores such as Apple Store), Or BlackBerry as well as Windows. In view point of the related works, we summarize it as follows:-

In $^{5,6}$ explained that electronic commerce dates to the last 30 years of the twentieth century. It relies on computers and the cluster network to become a necessity for the growth of the global, regional and local economies, which analysts consider to be factors affecting economic growth. The study aimed to shed light on the electronic commerce and its effects in the global economy and to identify the reality of electronic commerce in the Arab world, in addition to identify the most important risks to electronic commerce and the means to address them. The study considers that the Arab countries must unite and improve their economy and raise the challenge posed by communication technologies. They should open the way for e-commerce and take forward steps that are considered forward, thus contributing to opening wide horizons for Kuwaiti economic institutions to penetrate world markets. Exports outside the hydrocarbon sector and modernization of banking institutions, especially with regard to electronic payment methods.

The study ${ }^{z}$ has seen that in light of the economic conditions experienced by the Arab and Islamic countries, electronic commerce has become an urgent necessity and a developmental requirement to increase its contribution to foreign trade, as well as the development of its domestic production and marketing sectors and provide broad opportunities to raise their economic growth, The image of electronic commerce in the Arab world to a large extent from the rest of the world If we look at the reality of e-commerce in the Western world and the Arab world, as we find many Arab companies are still far from the practice of electronic commerce, where we find that most Arab countries Which lag behind electronic transactions. The study showed that the tremendous progress in the means of tele-communication and e-commerce has become a feature of the so-called new economy in order to achieve the hope of achieving a fair globalization in a non-traditional way, contrary to the traditional thought that there are stages necessary for the growth of the economy. Obtaining them will not be a hindrance to concerted efforts to acquire such modern technologies that can contribute to the activation and moving of their economies in line with the global economic data. Therefore, the urgent need to realize e-commerce is no longer an option we accept or reject, but it is an imperative necessity that imposes its presence on all economists and business owners in the world. In addition, the world as a whole must pay great attention to Arabic content in terms of language and cultural aspects to counter progress and rapid and successive revolutions in the world of ICT.

$\mathrm{In}^{\underline{8}}$ noted that trade in general has been known for many centuries. Different developments in this era are characterized by the increasing role of technology and the maximization of the benefits of modern technology known as electronic commerce. Services and electronic transactions. This trade has been able to spread significantly in a short period of time, its importance has increased and it has received general acceptance, and its international position in international trade relations has been taken faster than expected. Electronic commerce has become a reality not only in developed countries but also in all parts of the world.

The study finds that despite the increasing trends towards electronic commerce, this does not preclude saying that it involves many challenges that made the countries of the world do not benefit from electronic commerce to the same degree in experience. The study focuses on the experience of Algeria, And the desired start, and the adoption of this type of exchange is still modest and in its early stages. In spite of the measures taken by the State, Algeria's ride to the growth train, catching up with the countries in transition to technological progress and adopting electronic commerce needs to focus on a set of fundamentals and radical changes in various areas to overcome obstacles to the launching of such trade in Algeria. There is no electronic commerce without national strategies and policies covering technical, educational, rehabilitation, institutional and legal building issues.

The study ${ }^{9}$ attempted to identify the concept and definition of e-commerce, its characteristics and its impact on consumers, companies and the economy in general, and to identify the technological requirements of e-commerce, And the knowledge of the readiness of the Palestinian society to practice e-commerce, and to identify the legal environment for e-commerce in Palestine, and address the challenges facing e-commerce in Palestine. The study recommended that an appropriate legal environment for e-commerce be put in place, as well as the provision of advanced technological infrastructure, the provision of electronic payment tools, the need for companies to benefit from e-commerce in enhancing their position in the market and urging the government 
to develop appropriate solutions to the challenges facing e-commerce.

From the previous studies and after the presentation of the most important studies in the field of electronic commerce, we find that it focused mainly on two important points, the first emphasis on the importance of electronic commerce at the moment, and the second that the Arab environment still needs a lot of development to cope with them, especially as it has become a reality that is unavoidable to deal with and work on benefiting The study focuses on the impact of e-commerce on competition in the local Arab markets by highlighting the most important opportunities and challenges in this area. While this study will focus on the reality and the main challenges and major determinants in the activation and use of electronic applications in support of e-commerce in the community of the province of Al-Kamil.

\section{Research Problem and Objectives}

At a time when developed countries, including the United States and European countries, have gone a long way in the field of electronic commerce, we see that some Arab societies lag behind in this field and have not been able to absorb the idea and the importance of recent information. These societies have no importance for the information and e-commerce industry, which has made business organizations and companies concerned about the use of electronic commerce and in the absence of full awareness of individuals in terms of dealing with these modern means and the interest in the field of electronic commerce requires more Planning and scientific organization. In view of the rapid development of the concept of e-commerce and because it has become a real reality, we must deal with them, but there is a significant reluctance to use the Instagram in the society of the province of full, especially in the field of electronic commerce, and the problem of study in an attempt to identify the reality and limitations of the practice of electronic commerce Study Society. The importance of this research stems from the novelty of its subjects for the Instagram, and may emerge through.

- Access to theoretical and intellectual implications as a real response to one of the main issues and challenges faced by electronic applications in support of e-commerce in the community of the province of Al-Kamil.

- Identify the nature of electronic commerce and its characteristics and the possibility of society in the province of full application and benefit from them.

- Identify the determinants of e-commerce practice in Al-Kamil governorate.

The various assumptions that authors used it in this article are given as follows:-

- There is a statistically significant relationship between the applications of e-commerce and the customs and traditions of a full-fledged society.

- There is a statistically significant relationship between e-commerce applications and the comparative advantages and competitiveness of the organization.

- There is no relationship between the application of the information and the sale and purchase of products and services.

\section{The Suggested Research Methdology}

The descriptive analytical approach will be used to suit this study. The descriptive approach is related to the study of problems related to humanities. It is important to study some humanitarian and marketing issues. It is not limited to the human fields. It is used in the field of natural phenomena. It is limited to describing the phenomenon, collecting information, organizing and expressing it quantitatively. This phenomenon with other phenomena. To achieve the objectives of the research, the researcher designed a questionnaire in order to know the relationship between the levels of adoption of software applications and improve the electronic commerce of the same members of the community of the province. The questionnaire consists of two parts, as follows:

- The first part: Demographic questions: Any preliminary data for the sample of the study, including demographic characteristics of the sample such as age, marital status, specialization, and rate. These data help to identify the characteristics of the study community and may help to explain the results of the study.

- The second part: The preparation of several questions to measure time management and its impact 
on raising the efficiency of employees in government organizations in a number of paragraphs.

The data will be entered and processed statistically by the computer through the program of statistical social sciences "SPSS" and then the data will be analyzed and extract the results of the search. The used descriptive analytical approach is the method that depends on the analysis and study of a set of phenomena, and describes these phenomena accurately and specific description, and express them by giving them numerical characteristics, and writing tables and data to determine these phenomena and their correlation with other phenomena, where descriptive approach is a broad approach Includes several approaches and sub-methods.

This analytical descriptive approach includes all other curricula except the historical curriculum and the experimental curriculum, where the question of descriptive and virtual analysis is an existing and common issue in all types of scientific research. The descriptive approach is used in the study which describes and interprets the phenomena and the current situation. Hypotheses and testing of these hypotheses. This type of research is of great importance, especially in the field of human studies, where the views of people and their beliefs and attitudes are revealed, and their attitudes from a particular position, where the subject is used to find out the issue and a specific opinion related to a particular category, especially from the categories of society, To collect descriptive data on a given phenomenon.

The descriptive research is to link, interpret and categorize the data and to determine the quality of the relationship of variables, causes and trends. The results are drawn, and the results of these findings are investigated. The main objective of the descriptive curriculum is to know the present to draw and build a plan for the future. In which the events can be predicted for the future and what events and phenomena that will be studied, where it provides a picture of the extent of change in previous phenomena, through which the researcher can study the future, the descriptive studies a tremendous ability to predict but the ability remains limited, these social phenomena affect the rapid development and change of descriptive studies. Where descriptive research cannot stand at the limits of the diagnostic description; rather, it deals with what must be the phenomena addressed in the research, evaluates specific criteria and finds steps and methods to follow and walk on its approach to arrive at the correct image that should be in the presence of metrics and values Designated as standard research.

There are several steps taken by the researcher in general in the descriptive analytical approach and from these steps:

- The existence of a problem and data is collected on this problem that helps to solve this problem.

- Determine the nature of the information collected.

- To determine the hypotheses and questions related to the subject of the study.

- Identify the unclear aspects of the study.

- Determine the variables of the problem and the nature of their relationship.

\section{Electronic Applications with their Advantages and Reality}

Today's electronic applications are the goal of most programmers who need a source. They believe that they provide beginners and professionals with a simple interface, superior technology and fast access. They are available via an internet connection and can be accessed anytime, anywhere. The performance of most web applications is starting to improve. While most applications are free and only need an application link, some companies offer very sophisticated applications through a subscription, often monthly, so they can run the application from any device as soon as they enter the registration information they received after registration and pay the amount, some of these applications Are professional office software applications and others are advanced image editors.

It is known that the different operating systems on mobile vary between Android, IOS and Windows Phone, each of which has its own applications and independent electronic store, which is the largest platform to launch the applications of this type of operating systems. For example, in IOS there is an Apple Store and on Android there is Google Play and so on. Before entering into the world of smart phone applications, you should identify the most important platforms that will be called the application for your company. This means that the application programming method is compatible with different operating systems. The importance of Android application programming lies in the following privileges:- 
- Android applications are the world's most popular applications for smart phones, with the share of sales of Android phones in the third quarter of 2014 about $84.4 \%$.

- Android applications can be used on a wide range of businesses, such as banking, shopping, e-commerce, sports news, blogging and more.

- Android applications can be used to increase your brand's brand reputation, giving users and customers' additional options to interact with the app.

- Programming Android application for your company or business can increase the number of leads and sales and thus increase your company's profits

The electronic applications search for achieving the following:-

- Find information quickly and easily in rich content sites.

- Visitors are given the ability to search, organize, and navigate content in the way they see fit.

- Allows the collection, preservation and analysis of data provided by visitors.

- Extract and generate web-based reports for analysis.

There are many definitions of e-commerce some tend to narrow and some tend to expand and the most important are:

- E-commerce involves the exchange of products and services through an electronic intermediary, i.e the Internet and the World Trade Organization. It contains various activities for the production, distribution, marketing, sale or delivery of goods and services to the buyer through electronic media.

- According to this definition, business transactions include three forms of operations: product search, product demand and product delivery.

- Some economists believe that e-commerce is the means of communication and information between the commercial parties to complete business and transactions, through information communication, market service and virtual projects ${ }^{10}$.

- Some believe that e-commerce, in addition to what has been mentioned, and provides substantial flexibility for electronic networks. E-commerce has given new opportunities to all those who manage and manage business activities as well as the exploitation of digital information in the context of business activity. It also facilitates cooperation among different working groups. These groups can be a service that distributes information within the organization in order to develop a marketing strategy.

As for the benefits of electronic commerce to consumers are as follows ${ }^{11,12}$ :-

- E-commerce helps to understand the needs of customers and therefore offers shopping options in front of them widely and this is a cycle that achieves high satisfaction among customers compared to traditional trade. Note that the increasing number of customers offset by more space in the markets for suppliers.

- E-commerce helps to create a great incentive to increase competitiveness. And stimulate the interest of researchers to find ways and methods of sophisticated use of vouchers and electronic checks in addition to improving the competitiveness of suppliers in the field of product quality for customers.

- Shortening the commercial cycle as it is shipped directly from the factory to the end consumer, which saves costs and shortens the time for suppliers in addition to the rapid response to the needs of consumers, especially electronic goods such as magazines and newspapers in addition to the associated reduction in prices.

- It allows participation in virtual auctions.

- It allows customers to exchange experiences and opinions and to receive advice from intermediaries via the Internet.

- Electronic commerce facilitates the distribution of public services such as health, education and other social services at low prices and high efficiency.

- It allows people living in Third World countries to own products and goods that are not available in their countries of origin and can also obtain university degrees via the Internet.

- It allows the individual to work at home and reduces the time available for shopping which means less traffic congestion in the streets and this helps to reduce the percentage of environmental pollution.

- It allows some commodities to be sold cheaply so that individuals with low incomes can buy such goods, which means they contribute to raising the standard of living of the society as a whole. 


\section{Instgram Application with its Major Pros \& Cons}

Among many social networks, one particular choice without the other may be a very confusing choice in terms of being the perfect marketing and advertising business. Each platform has its loyal admirers and followers and each contains its distinctive characteristics that may be of great importance to your business. Here is the everpresent question about which platforms are best for your business: Instagram or Facebook? Your choice of one platform is something you should give a lot of thought and analysis. Before deciding which is best for your business: Instagram or Facebook, let's first make a comparison between the two. Referring to the benefits of both, so that the decision to choose the most suitable platform becomes clear to you. Here are some of the benefits of marketing Instagram:-

- There are nearly 700 million people with Instagram accounts worldwide, which mean a wider range of communication.

- More than 400 million of them use it daily, sharing photos and videos actively, following brands to their favorite products.

- Since 2010 Instagram has developed an on-air broadcast feature. This gives you the opportunity to immediately see all your followers to keep them up-todate.

- Instagram is known for its high connectivity worldwide, in proportion to the large numbers of its users worldwide.

- Instagram is the most attractive audience compared to all other social networks, including Facebook itself.

- According to a recent study, Instagram brings visitors to websites more than any other network. Which increases the likelihood of increasing the number of visitors to your site.

- Instagram is unique in attracting the younger audience that you can target through your advertising campaign.

Instagram is a free photo sharing and social networking application launched in October 2010 that allows users to take a picture, add a digital filter to it, and then share it in a variety of social networking services, including Instagram itself. The images are added to the square shape, similar to the Kodak Instamatic and Paula
Rued images, in contrast to the 4: 3 aspect ratio commonly used by mobile phone cameras. In the beginning, support for Instagram on the iPhone, iPad and iPod Touch, in April 2012, added support for the Android platform, 2.2 or higher. It is distributed through iTunes Store and Google Play. In June 2013, the video imaging application was developed intermittently for users ${ }^{\frac{13}{3}}$.

In December 2010, the application received one million users and after one year in 2011 the application has increased $500 \%$ of users to reach 5 million users and in the third year to implement the number doubled, especially with the launch of the application for Android platform, exceeding the number of users 30 million users On December 12, 2014, the social networking service "Facebook" reported that it exceeded the threshold of 300 million users in July 2011, users of the application raised 100 million images, and in August of the same year the number of images uploaded to 150 million images i.e during one month and in May 2012, the following were announced:

- Every second, 58 new images are added.

- In a second, the network gets a new user.

- The application has surpassed the 1 billion mark raised since it was opened

The features of photo sharing Instagram Arabic program are given as follows:-

- Supports Arabic and $100 \%$ free.

- Easy and simple to use.

- You can edit photos and videos for free with the most beautiful filters.

- More than 10 creative tools for editing on images.

- You can share your photos on Facebook and Twitter at the same time.

- Upload videos and photos with unlimited number.

- You can make a reference to friends on the image to increase interaction.

- Allows you to lock your account and make it private to see followers of your account on the intranet only ${ }^{14}$.

In view points of Pros and Cons of Instagram, it is summarized as follows: -

The Pros are:-

- Ease of communication and speed with whom you want from the personalities of scientists or elders or 
students of science or politicians or writers, analysts or journalists.... etc.

- Easy to follow the events and the latest news and updates.

- Ease of use in the field of advocacy and dissemination of tips, recommendations, books and research.

- Turning the world into a mini-network in which people of all races easily communicate.

\section{The Cons are:-}

- Discussions and debate, which is useful only to challenge and insult and harassment among Muslims.

- Uncover the secrets and know all about what is going on even in things that are best kept.

- Addiction to some degree of forgetting male and worship ${ }^{15}$.

- Utilize it from some of the people's shrewdness in spreading sedition, lying and rumors.

\section{Methodological Framework of the Article and Analysis of Numerical Results}

This section aims to describe the scientific methods used in this study for data collection and analysis. The chapter will also present the scientific research philosophy used in this study, namely, the role of applications in supporting e-commerce. Then talk about the field study environment in terms of sample, community and questionnaire. The qualitative and descriptive approach presented in this article was based on the description of the phenomenon and its characteristics. The quantitative expression by describing the phenomenon is a numerical description indicating the extent of its existence., Their size and degree of correlation with other variables, and then access to the results, analysis, and interpretation.

The results of the questionnaire prepared for this purpose, which were supervised by the researcher and some of the faculty members in the faculty, were carefully prepared, formulated and produced. The weight of each of the closed-answer questionnaire was given using the five-expressions.

Also, This article used the analytical descriptive approach, which defines the type of research by which all members of the research community or a large sample of them are questioned in order to simplify the presentation of the data extracted from the study tool where the questionnaires were encoded and entered into the computer using the SPSS program to obtain the frequencies and percentages And standard deviations to answer the study questions and to describe the study sample.

The validity of the internal consistency of the questionnaire (structural honesty) was calculated by calculating Pearson correlation coefficients between the total score and the paragraphs of the questionnaire. The correlation coefficients are significant at $(0.01)$, indicating that the terms of the study are linked among them and is considered a true measure of what is put to measure. Finally, the stability of the instrument was verified using the formula of the ALPHA KRONBACH internal consistency coefficient, which is based on the variations of the test questions. It requires that the test items measure only one feature. The aim of this step is to verify the results consistently if the study is returned to another sample under the same conditions. The statistical value of the CRONBACH ALPHA factor is $60 \%$ or more so that the researcher can disseminate the results to all members of the community. Therefore, the researcher calculated the stability factor for all the paragraphs of the questionnaire, and then calculates with $\mathrm{Ml}$ overall measure of stability.

The results indicate that the stability coefficients of respondents' responses to the role of electronic applications in supporting e-commerce at a total stability of 0.735 all indicate a very high reliability in the reliability and stability of the study tool. We conclude from the above that the study instrument met the psychometric conditions of good testing and that it meets the purposes of the study.

- Analytical Statistics: Analysis of the study data is a statistical analysis that achieves its objectives and tests its hypotheses using the following treatment methods.

- Descriptive statistics: descriptive statistical measures included frequency, percentage, weighted arithmetic mean, and standard deviation.

- Indicative statistics: The measures of the explanatory statistics included Pearson correlation coefficient to measure the validity of the study instrument and the degree of correlation of each paragraph with the total number of the axis to which it belongs. (ANOVA), i.e the F-TEST test, as well as the T-TEST test. 
Finally the author reaches to the following main outcomes:-

- There is an existence of a relationship between the applications of e-commerce and the customs and traditions of the Saudi society in the province of $\mathrm{Al}$ Kamil governance.

- There is a statistically significant relationship between e-commerce applications and the comparative advantages and competitiveness of the organization.

- There is an inverse relationship between the application of the information and the sale and purchase of products and services.

\section{Concluded Comments and Recommendations}

The Instagram is the largest social network for photo sharing throughout the world. There are many filters that can be used to customize your images to appear in a style that distinguishes you from others, making this application a great editing program. In addition to this unique feature of the brand, the application also allows users to post videos and other material on the profile page. The benefits of Instagram are so many advantages that many people are aware of these benefits and are helping them make money. As well as the potential for social growth and development within this social network, it is also possible to attract ever-increasing numbers of followers. Best of all is the possibility of sharing tastes and preferences as well as ideas that contribute to the development of trends and trends and thus reach the desired target audience. To help you use this social network, we have mentioned many great features for using Instagram. These features are very numerous, and every feature deserves to be mentioned in detail and explained, as well as by users.

In light of the results of the previous study, and after completing the answer to the questions of the study, the researcher finds a set of recommendations calling for taking into account as a future work to be done by others:-

- Adopting the technology education policy for the members of the society in Al-Kamil governorate to demonstrate the importance of electronic commerce through training and education programs in professional and administrative institutions, with the interest of spreading technical awareness in educational and academic institutions in accordance with customs and traditions.

- To carry out some activities within the training programs for e-commerce to stimulate the community to enter this area and give them good ideas that fit with the nature of the conservative community in the province, which is expected to succeed according to the needs of the labor market.

- Solving the obstacles facing the spread of e-commerce in non-civil societies by providing fast internet, and raising awareness of the importance and benefits of e-commerce and keeping abreast of global developments in the process of marketing products through the Internet.

- Conduct further studies in the field of e-commerce to cover all companies and businesses and to spread the benefit to society.

\section{Acknowledgement}

This paper has been presented and discussed during the International Conference on Communication, Management and Information Technology- ICCMIT 2019, Vienna, Austria.

\section{References}

1. Najm AN. E-management strategy, functions and problems, Riyadh, Dar Al-Marikh Publishing; 2004.

2. Ghoneim, AM. Electronic management horizons of the present and future prospects, Mansoura. The Egyptian Library: Second Edition; 2004.

3. Qandilji AI. E-commerce and its applications. Dar Al-Masirah for publication and distribution: Jordan; 2016.

4. Koutua HS. Administrative information systems. Jeddah, King Fahd National Library; 2004.

5. Al-Awadhi AA. Factors affecting marketing and e-commerce. Journal of Economics and Society. 2010; 6.

6. Alioh. E-Commerce and marketing skills. Dar Al-Ameen Publishing; 2002.

7. Allam R. Obstacles to the development of electronic commerce in the Arab World Case Study of Algeria, Master Thesis, British Arab Academy for Higher Education; 2010.

8. Dimesh S. E-commerce reality and reality in Algeria, Master Thesis, University of Mentori-Constantine, Faculty of Economic Sciences and Facilitation Sciences; 2011. 
9. Jibril SS. The reality of e-commerce in Palestine and future challenges, Master Thesis, Gaza: Al-Azhar University, Faculty of Economics and Administrative Sciences; 2012.

10. E-Commerce [Internet]. [cited 2019 Mar 07]. Available from: https://en.wikipedia.org/wiki/E-commerce.

11. Ahmed M. The difficulties facing Arab electronic commerce from the point of view of Arab Electronic Store Owners, King Saud University Journal, Administrative Science; 2002.
12. Hadi A, Hafiz IA. Proposed framework for tax adjustments for the transition to the world of electronic commerce. Theory and Field Study; 2000.

13. Nour B. Fundamentals of electronic commerce. Arabic Encyclopedia of Computers and the Internet; 2002.

14. Melhem MF. E-Commerce and the Jordanian Banking Sector. Journal of Banks in Jordan. 2000; 19(6).

15. Zoghebi S. The role of electronic management applications in improving administrative decisions, Master of Administrative Sciences. Faculty of Social and Administrative Sciences, Riyadh; 2006. 